\title{
Evidence of Pyrethroid Resistance in Eggs of Pediculus humanus capitis (Phthiraptera: Pediculidae) from Argentina
}

\author{
GASTÓN MOUGABURE CUETO, ${ }^{1,2}$ EDUARDO NICOLÁS ZERBA, ${ }^{1,3}$ aNd MARÍA INÉS PICOLLO ${ }^{1}$
}

\section{J. Med. Entomol. 45(4): 693-697 (2008)}

\begin{abstract}
Insecticide resistance in Pediculus humanus capitis De Geer 1778 (Phthiraptera: Pediculidae) from different countries has been well documented in the last years. Otherwise, little research has been reported about insecticide resistance in insect embryos and none in human louse embryos. In this work, we studied insecticide resistance in eggs of three head lice populations whose pyrethroid resistance was shown in adults and nymphs compared with a susceptible laboratory body louse strain. All head louse populations showed high permethrin resistance in eggs. Levels of permethrin resistance (LCRs) assessed in eggs by immersion technique were higher than those previously reported for the corresponding populations of adults by topical application. Comparison of LCR values for different populations showed that there was a direct relationship between the resistance levels assessed in eggs and those in adults. All permethrin-resistant eggs showed high resistance to dphenothrin and dichloro-diphenyl-trichloroethane (DDT) and low resistance to carbaryl, which is in common with the resistance profile established for adults and nymphs. The results concerning the high resistance to pyrethroid (permethrin and d-phenothrin) and the cross-resistance to DDT and carbaryl detected in head louse eggs and adults suggested similar resistance mechanisms in eggs and adults of head louse populations from adults.
\end{abstract}

KEY WORDS head lice, resistance, insecticide, eggs, pyrethroids

The failure in the chemical control of Pediculus humanus captis De Geer 1778 has been attributed to evolution of insecticide resistance. Resistance to organochlorinated insecticides was shown in the 1960s (Maunder 1971), and resistance to the widely used pyrethroid insecticides was reported in several countries (Coz et al. 1993, Burgess 1995, Mumcuoglu et al. 1995, Rupes et al. 1995, Picollo et al. 1998, Downs et al. 1999, Pollack et al. 1999, Lee et al. 2000, Tomita et al. 2003). These studies were focused on the evaluation of resistance in the larval or adult stages of the head lice. However, the insecticide resistance in embryos should not be underestimated as a contributive cause of control failures.

Despite the fact that the majority of the insecticides are directed to larval and adult stages, the eggs can be exposed to the insecticides as well. If the insecticides reach the embryo and exert some toxic effect, the embryos will be under selection pressure and may develop their own resistance mechanisms. However, the biochemical process involved in adult resistance can manifest in the embryos despite their not having been in contact with the insecticide.

\footnotetext{
${ }^{1}$ Centro de Investigaciones de Plagas e Insecticidas (CITEFA CONICET), Juan Bautista de La Salle 4397, B1603ALO Buenos Aires, Argentina.

${ }^{2}$ Corresponding author, e-mail: gmougabure@citefa.gov.ar.

${ }^{3}$ Universidad Nacional de General San Martín, Escuela de Postgrado, Buenos Aires, Argentina.
}

Despite the importance of the established problem, little research has been reported about insecticide resistance in embryos and none in human lice embryos. Leonard et al. (1991) reported pyrethroid resistance in eggs of two populations of Helliothis virescens Fabricius, whose pyrethroid resistance was assessed in third instars. Ho and Goh (1984) showed that recently hatched larvae and eggs of Plutella $x y$ lostella $\mathrm{L}$ from a pyrethroid-resistant population were resistant to deltamethrin. Grosscurt (1980) obtained resistant eggs after laboratory selection with diflubenzuron in Musca domestica L.

The aim of this research was to study insecticide resistance in eggs of $P$. humanus capitis populations whose pyrethroid resistance was shown in postembryonic stages. Moreover, the resistance profile to pyrethroid and nonpyrethroid insecticides was comparatively studied in adults and eggs.

\section{Materials and Methods}

Biological Material. Adults nymphs and eggs of the head lice P. humanus capitis (HL) were collected from heads of infested children (6-12 yr old) from three elementary schools in several areas of Buenos Aires, Argentina, using a fine-toothed anti-louse comb (Nopucid; Laboratorio ELEA, Buenos Aires, Argentina) according to a protocol approved by an ad hoc committee of the Research Center of Pests and Insecticides. After collection, the head lice eggs were sent to 
Table 1. Susceptibility values and resistance levels (LDR) to permethrin in eggs and adults of human lice

\begin{tabular}{|c|c|c|c|c|c|c|}
\hline Stage & Population & $n$ & Slope $\pm \mathrm{SE}$ & $\mathrm{LD}_{50}$ or $\mathrm{LC}_{50}{ }^{a}(95 \% \mathrm{CL})$ & $\chi^{2}$ & LDR or LCR (95\% CL) \\
\hline \multirow[t]{4}{*}{ Adults $s^{b, c}$} & S-BL & 120 & $4.3 \pm 1.10$ & $2.4(1.86-3.77)$ & 0.07 & - \\
\hline & BA-HL & 60 & $2.12 \pm 0.160$ & $40.2(34.05-47.47)$ & 0.08 & $16.6(11.78-23.42)$ \\
\hline & HB-HL & 80 & $1.6 \pm 0.91$ & $114.1(55.50-221.04)$ & 21.02 & $47.2(33.79-65.81)$ \\
\hline & GH-HL & 80 & $1.69 \pm 0.100$ & $642.6(321.39-1,033.25)$ & 7.08 & $265.6(192.20-367.06)$ \\
\hline \multirow[t]{4}{*}{ Eggs } & S-BL & 180 & $1.44 \pm 0.070$ & $0.004(0.0026-0.0053)$ & 2.16 & - \\
\hline & BA-HL & 80 & $0.47 \pm 0.054$ & $3.3(2.13-5.21)$ & 2.31 & $884(552-1,415)$ \\
\hline & HB-HL & 120 & $0.64 \pm 0.105$ & $14.1(-)$ & 2.10 & $3,760(1,941-7,289)$ \\
\hline & GH-HL & 120 & $1.93 \pm 0.12$ & $18.3(10.97-64.35)$ & 99.6 & $4,876(3,990-5,959)$ \\
\hline
\end{tabular}

${ }^{a} \mathrm{LC}_{50}$ for eggs expressed in percentage wt:vol and $\mathrm{LD}_{50}$ for nymphs and adults in $\mathrm{ng} /$ insect.

${ }^{b}$ Data reported by Mougabure Cueto et al. (2006b).

${ }^{c}$ Adults and third instars combined.

the laboratory where adults and late development eggs were selected and immediately used in the bioassays. Selected eggs showed black eyes, clearly visible appendages, and internal movements of the embryo (Mougabure Cueto et al. 2006a). The populations were selected according to the resistance levels to permethrin assessed in previous studies (Picollo et al. 1998, 2000, Vassena et al. 2003). Lice from Bandera Argentina (BA-HL) were the least permethrin resistant, lice from Guardia de Honor (GH-HL) were the most permethrin resistant, and lice from Hogar Belgrano (HB-HL) had intermediate resistance. The protocol for lice collection was approved by the ad hoc committee of Research Center of Pest and Insecticides (Buenos Aires, Argentina) and filed in our laboratory.

Because pyrethroid-susceptible strains of head lice were not available for resistance, a susceptible strain of body lice (S-BL) was used, based on the similarity in pyrethroid susceptibilities of strain of body lice and head lice with no history of exposure (Mumcuoglu et al. 1990, Downs et al. 2000). Our louse colony originated from one reared in the Department of Parasitology, University of Queensland, Queensland, Australia, and was maintained at $28 \pm 0.5^{\circ} \mathrm{C}$ and $50-60 \%$ $\mathrm{RH}$. The eggs in late stages were selected according to Mougabure Cueto et al. (2006a).

Because adults and third instars have been shown to be equally susceptible (Mumcuoglu et al. 1990), bioassays were performed on the two stages combined. For ovicide bioassays, late-development eggs were selected according to the appearance of black eyes and appendages as reported by Mougabure Cueto et al. (2006a).

Chemicals. Technical grade permethrin $(42.5 \%$ cis$54.2 \%$ trans; Chemotecnica, Buenos Aires, Argentina), d-phenothrin (94.4\%; Sumitomo Chemical, Osaka, Japan), carbaryl (98\%; Rhone Poulenc, Lyon, France), and dichloro-diphenyl-trichloroethane (DDT) (standard; Dr. Ehrenstorfer, Augsburg, Germany) were used. Serial dilutions of the insecticides in acetone (Merck, Buenos Aires, Argentina) were prepared for the topical and immersion bioassays.

Bioassay with Eggs. Toxicity in eggs was evaluated using the immersion technique reported by Mougabure Cueto et al. (2006a). Ten late eggs were fixed to a microscope slide by double-faced adhesive tape. The slides containing eggs were immersed for $10 \mathrm{~min}$ in 10 $\mathrm{ml}$ of different concentrations of insecticide in acetone. Final concentrations ranged from 0.0005 to $35 \%$ wt:vol for permethrin, from 0.01 to $50 \%$ wt:vol for d-phenothrin and DDT, and from 0.01 to $1 \%$ wt:vol for carbaryl. Each concentration was replicated at least three times. Control eggs were immersed for $10 \mathrm{~min}$ in pure acetone. After the exposure, the microscope slides with the eggs were dried on filter paper and incubated at the optimal laboratory condition for each species $\left(28 \pm 0.5^{\circ} \mathrm{C}\right.$ and $75 \% \mathrm{RH}$ for head lice and $28 \pm$ $0.5^{\circ} \mathrm{C}$ and $50-60 \% \mathrm{RH}$ for body lice) (Mougabure Cueto et al. 2006a). Mortality data for treated eggs were recorded $5 \mathrm{~d}$ after the eclosion of controls. The criterion for embryo mortality was no eclosion.

Bioassay with Nymphs and Adults. Tests to determine insecticide susceptibility in third instar and adults were done by topical application, according to the method reported by Vassena et al. (2003). Each louse was treated with $0.1 \mu$ l of the insecticide solution on the dorsal abdomen using a 5- $\mu$ l Hamilton syringe provided with a repeating dispenser. Concentrations ranged from 0.003 to $90 \mathrm{mg} / \mathrm{ml}$ for d-phenothrin, from 0.01 to $1 \mathrm{mg} / \mathrm{ml}$ for carbaryl, and from 0.5 to $50 \mathrm{mg} / \mathrm{ml}$ for DDT. Each dose was replicated at least three times. Treated insects were placed onto a 55-mm-diameter Whatman no. 1 filter paper disc moistened with $0.5 \mathrm{ml}$ water, which were placed in the bottom of a plastic petri cage. Ten insects were used for each concentration in each independent test. Topical application with acetone was made for controls. After treatment, insects were placed at $18 \pm 0.5^{\circ} \mathrm{C}$ and $70-80 \% \mathrm{RH}$ for head lice and $28 \pm 0.5^{\circ} \mathrm{C}$ and $50-60 \% \mathrm{RH}$ for body lice, with the lights off. Mortality was recorded at $18 \mathrm{~h}$ (Picollo et al. 1998). The criterion for mortality was inability to walk from the center to the border of a 7-cm-diameter filter paper disc.

Statistical Analysis. Mortality data were corrected using Abbott's formula (Abbott 1925). Concentration-mortality data from egg immersion tests and dose-mortality data from topical tests were subjected to probit regression analysis (Litchfield and Wilcoxon 1949) using POLO PC (LeOra Software 1987). Lethal concentration ratio (LCR) or lethal dose ratio (LDR) and $95 \%$ CL were calculated as described by Robertson and Preisler (1992) (probit response level $\pi=5$ ). 


\section{Results}

Susceptibility values $\left(\mathrm{CL}_{50}\right.$ or $\left.\mathrm{DL}_{50}\right)$, slopes of probit regression, and LCR or LDR to permethrin in eggs and adults (adults and third instars) of human lice are shown in Table 1. All head lice populations showed high levels of permethrin resistance in both eggs and adults. Resistance levels in eggs (LDR: 884-4,876) were higher than those previously reported for adults (LDR: 16.6-265.6) (Mougabure Cueto et al. 2006b). In both stages, the resistance levels of BA-HL were the lowest and those of GH-HL were the highest.

Susceptibility values, slopes, and LDR to d-phenothrin, DDT, and carbaryl in adults of head and body lice are shown in Table 2. High resistance to d-phenothrin (LDR: 8.2-974.7) and DDT (LDR: 25.3 to >74.6) and low resistance to carbaryl (LDR: 1.2-1.6) were found in all head louse populations.

Susceptibility values, slopes, and LCR to d-phenothrin, DDT, and carbaryl for head and body lice eggs are shown in Table 3. High levels of resistance to d-phenothrin (LCR: 173-1,433) and DDT (LCR: 118.6 to $>400$ ) and low resistance to carbaryl (LCR: 4.44.9) were found in the permethrin-resistant eggs.

\section{Discussion}

Permethrin resistance in postembryonic stages of head lice from Argentina was previously reported ( $\mathrm{Pi}-$ collo et al. 1998, 2000; Vassena et al. 2003). This study showed permethrin resistance in eggs from those populations whose resistance to permethrin was assessed in nymphs and adults. Moreover, the eggs from these populations were resistant to d-phenothrin and DDT, as in the corresponding postembryonic stages.

Comparison of LDR values showed that there was a direct relationship between the levels of resistance assessed in eggs and adults (BA-HL is the lowest and GH-HL the highest), showing a similar expression of resistance in both stages of development (Fig. 1). Moreover, the LDRs for eggs were always higher than those estimated, in the same population, for adults (Fig. 1). This result could be caused by an actual higher resistance or to different methodologies applied to eggs (immersion technique) and adults (topical application). Different methods of exposition to insecticide determines differences in the toxicokinetic and toxicodynamic processes involved during intoxication; thus, the relative importance of each toxicokinetic or toxicodynamic process will change with the exposition method (Scharf et al. 1995, Vassena et al. 2003). Another factor to consider is that the body louse eggs have more aeropyles openings in the eggshell cap than the head louse eggs (Buxton 1946).

Similarly, differences in resistance levels were previously found in eggs and larvae of pyrethroid-resistant Heliothis virescens Fabricius (Leonard et al. 1991). These authors reported that resistance to lambdacyhalothrin in eggs $(11.7 \times)$ of a field strain (FIELD-89) measured by dipping technique were significantly higher than resistance to the same insecticide on the third larvae $(1.3 \times)$ evaluated by topical application.

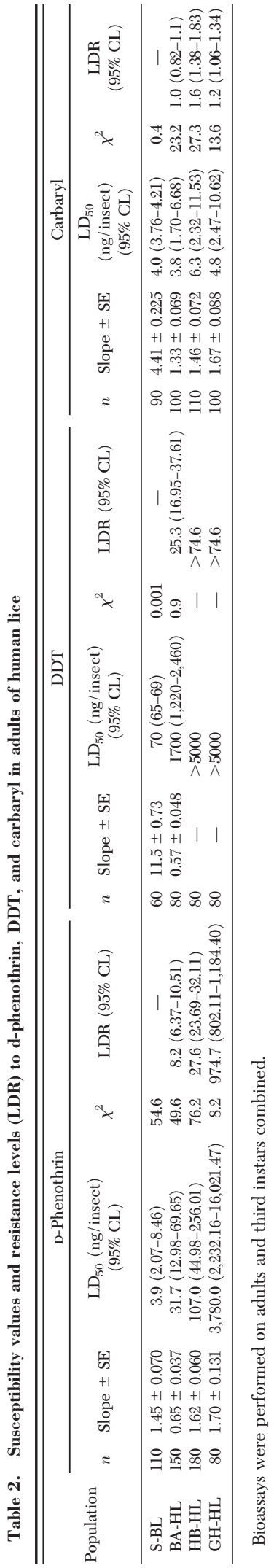




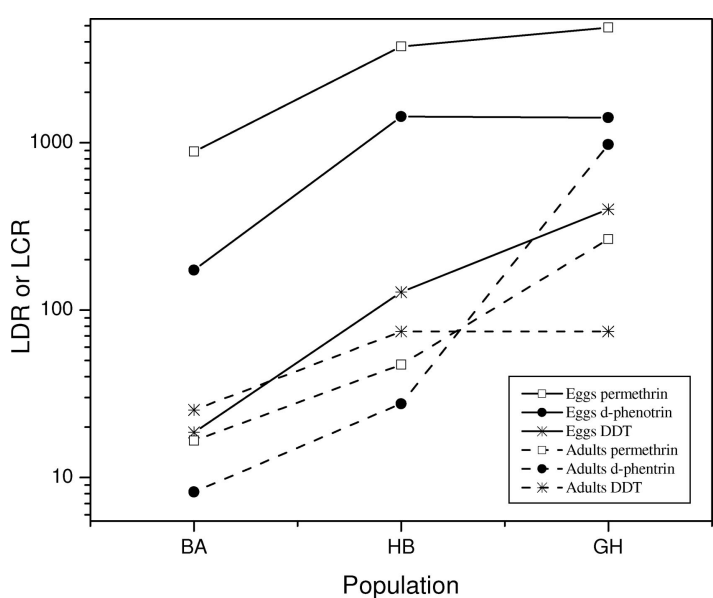

Fig. 1. Lethal dose ratio and lethal concentration ratio in each population and each insecticide.

Ho and Goh (1984) showed that both the eggs and the newly emerged larvae of the resistant strain of Plutella xylostella L. were more resistant to deltamethrin than those of the susceptible strain. These authors suggested that resistance appears very early in the life cycle of the insect.

In this study, the high resistance to pyrethroids (permethrin and d-phenothrin) and DDT detected in head louse eggs and adults suggested a cross-resistance phenomenon. Because pyrethroids and DDT share the site of action (sodium voltage-gated channel) and oxidative metabolism (P450 complex), the resistance could be based on these mechanisms. Also, the low resistance to carbaryl (an insecticide that had never been used as pediculicide in Argentina) could be based on the enhanced oxidative mechanism selected by pyrethroid pressure.

Hemingway et al. (1999) reported resistance to pyrethroids and DDT in adult head lice. These authors showed weak enhanced activity of glutathione-transferase and P450 complex, and lack of enhanced esterase activity. They suggested kdr-like as the principal resistance mechanism. Picollo et al. (2000) showed that adults and nymphs of $P$. humanus capitis were resistant to pyrethroids and susceptible to carbaryl. In that study, the in vivo treatment with inhibitors of oxidative and hydrolytic enzymes produced partial reversion of resistance, suggesting enhanced metabolism and altered site of action as resistance mechanisms. In a further study, González Audino et al. (2005) showed that monooxygenase activity was significantly correlated with the levels of resistance to permethrin in $P$. humanus capitis field populations from Argentina. Lee et al. (2000) showed that permethrin-resistant populations of head lice were susceptible to malathion. In that study, the synergism assay indicated a possible role of oxidative metabolism in the permethrin resistance, but mortality and knockdown bioassay suggested that nerve insensitivity was a principal resistance mechanism. The authors identified two point mutations in the para-orthologous 
louse sodium channel $\alpha$-subunit (T929I and L932 F), which were associated with knockdown resistance.

Results presented here showed high resistance to pyrethroids in eggs of $P$. humanus capitis, in common with that assessed for nymphs and adults. Additionally, results concerning the cross-resistance to DDT and carbaryl suggested that altered site of action and increased oxidative metabolism are the causes of insecticide resistance in head louse populations in Argentina.

\section{Acknowledgments}

We thank M. Mantesi, R. Flores, I. Cañete, and the authorities of the schools where head lice were collected. This research received financial support from Agencia Nacional de Promoción Científica y Tecnológica (Argentina), Consejo Nacional de Investigaciones Científicas y Técnicas (Argentina), and Laboratorio ELEA SACIFyA (Argentina).

\section{References Cited}

Abbott, W. S. 1925. A method of computing the effectiveness of an insecticide. J. Econ. Entomol. 18: 265-267.

Burgess, I. 1995. Pediculus humanus capitis in schoolchildren. Lancet 345: 730-731.

Buxton, P.A. 1946. The louse: an account of the lice which infest man, their medical importance and control, 2nd ed. Edward Arnold \& Co., London, United Kingdom.

Coz, J., C. Combescot-Lang, and V. Verdier. 1993. Resistance du pou tete Pediculus capitis L. 1758 aux pyrethrinoides d-phenotrine et permethrine en France. Bull. Soc. Fr. Parasitol. 2: 245-252.

Downs, A.M.R., K. A. Stafford, I. Harvey, and G. C. Coles. 1999. Evidence for double resistance to permethrin and malathion in head lice. Br. J. Dermatol. 141: 508-511.

Downs, A.M.R., K. A. Stafford, and G. C. Coles. 2000. Susceptibility of British head lice, Pediculus capitis, to imidacloprid and firponil. Med. Vet. Entomol. 14: 105-107.

González Audino, P., S. Barrios, C. Vassena, G. Mougabure Cueto, E. N. Zerba, and M. I. Picollo. 2005. Increased monooxygenase activity associated with resistance to permethrin in Pediculus humanus capitis (Anoplura: Pediculidae) from Argentina. J. Med. Entomol. 42: 342-345.

Grosscurt, A. C. 1980. Larvicidal and ovicidal resistance to diflubenzuron in the housefly (Musca domestica). Proc. Kon. Ned. Akad. Van Weten. 83: 127-141.

Hemingway, J., J. Miller, and K. Y. Mumcuoglu. 1999. Pyrethroid resistance mechanisms in the head louse Pediculus capitis from Israel: implications for control. Med. Vet. Entomol. 13: 89-96.

Ho, S. H., and P. M. Goh. 1984. Deltamethrin as a potencial ovicidal pyrethroid against Plutella xylostella L. Toxicol. Lett. 22: 161-164.

Lee, S. H., K. Yoon, M. S. Williamsom, S. J. Goodson, M. Takano-Lee, J. D. Edman, A. L. Devonshire, and M. Clark. 2000. Molecular analysis of kdr-like resistance in permethrin-resistant strain of head lice, Pediculus capitis. Pestic. Biochem. Physiol. 66: 130-143.

Leonard, B. R., J. B. Graves, and T. C. Sparks. 1991. Ovicidal effects of selected insecticides against pyrethroid-suscep- tible and -resistant tobacco budworm. Southwest. Entomol. 15: 163-172.

Litchfield, J. T., and F. Wilcoxon. 1949. A simplified method of evaluating dose-effect experiments. J. Pharmacol. Exp. Ther. 96: 99-110.

Maunder, J. W. 1971. Resistance to organochlorine insecticides in head lice and trials using alternative compounds. Med. Officer 125: 27-29.

Mougabure Cueto, G., E. Zerba, and M. I. Picollo. 2006a. Embryonic development of human lice: rearing conditions and susceptibility to spinosad. Mem. Inst. Oswaldo Cruz. 101: 257-261.

Mougabure Cueto, G., E. Zerba, and M. I. Picollo. 2006b. Permethrin-resistant head lice (Anoplura: Pediculidae) in Argentine are susceptible to spinosad. J. Med. Entomol. 43: 634-635.

Mumcuoglu, K. Y., J. Miller, and R. Galum. 1990. Susceptiblity of the human head and body louse, Pediculus humanus (Anolplura: Pediculidae) to insecticides. Insect Sci. Appl. 11: 223-226.

Mumcuoglu, K. Y., J. Hemingway, J. Miller, I. Ioffe-Uspensky, S. Klaus, F. Ben-Ishai, and R. Galun. 1995. Permethrin resistance in the head louse Pediculus capitis from Israel. Med. Vet. Entomol. 9: 427-432.

Picollo, M. I., C. Vassena, A. Casadío, J. Mássimo, and E. N. Zerba. 1998. Laboratory studies about susceptibility and resistance to insecticides in the head lice Pediculus capitis. J. Med. Entomol. 35: 814-817.

Picollo, M. I., C. Vassena, G. Mougabure Cueto, M. Vernetti, and E. N. Zerba. 2000. Resistance to insecticides and effects of synergists on permethrin toxicity in Pediculus capitis (Phthiraptera, Pediculidae) from Buenos Aires. J. Med. Entomol. 37: 721-725.

Pollack, R. J., A. Kiszewski, P. Armstrong, C. Hahn, N. Wolfe, H. Rahman, K. Laserson, S. Telford, and A. Spielman. 1999. Differential permethrin susceptibility of head lice sampled in the United States and Borneo. Arch. Pediatr. Adolesc. Med. 153: 969-973.

Robertson, J. L., and H. K. Preisler. 1992. Pesticide bioassays with arthropods. CRC, Boca Raton, FL.

Rupes, V., J. Moravec, J. Chmela, J. Ledvinka, and J. Zelecova. 1995. Resistance of head lice Pediculus capitis to permethrin in the Czech Republic. Centr. Eur. J. Publ. Health 3: $30-32$

Scharf, M. E., G. W. Bennett, L. R. Byron, and Chunfu Qui. 1995. Comparisons of three insecticide resistance detection methods for the German cockroach (Dictyoptera: Blattellidae). J. Econ. Entomol. 88: 536-542.

Tomita, T., N. Yaguchi, M. Mihara, M. Takahashi, N. Agui, and S. Kasai. 2003. Molecular analysis of a para sodium channel gene from pyrethroid-resistant head lice, Pediculus humanus capitis (Anoplura: Pediculidae). J. Med. Entomol. 40: 468-474.

Vassena, C. V., G. Mougabure Cueto, P. González Audino, R. A. Alzogaray, E. N. Zerba, and M. I. Picollo. 2003. Prevalence and levels of permethrin resistance in Pediculus humanus capitis De Geer (Anoplura: Pediculidae) from Buenos Aires, Argentina. J. Med. Entomol. 40: 447450.

Received 22 January 2007; accepted 6 March 2008. 